\title{
Optimization of the truss beam. Verification of the calculation results
}

\author{
Glib Vatulia ${ }^{1}$, Sophia Komagorova $^{1 *}$, and Mykhailo Pavliuchenkov ${ }^{1}$ \\ ${ }^{1}$ Ukrainian State University of Railway Transport, 61050 Feierbakh Sq. 7, Kharkiv, Ukraine
}

\begin{abstract}
The article presents a comparison of results of optimized calculation of a truss beam which was chosen as a combined construction. The results of calculation of a beam are compared using the method based on the properties of spacer systems and the calculation of the construction designed in LIRA software complex. The article is dedicated to verification of adequacy of the results of theoretical calculations of construction optimization. Values of longitudinal forces and bending moments appearing in a truss beam are chosen as convergence criteria. Two variants of construction loading are considered: a truss beam exposed to constant load only and a truss beam exposed to constant and temporary load. In the case under consideration, the minimum value (weight) of construction is an optimality criteria, variable parameters include beam panel length and camber height of a trussing rod. As a result, the construction will be considered optimal, if bearing and maximal (between the pillars) bending moments are equal in it. The result of verification of the obtained data is the value of error.
\end{abstract}

\section{Introduction}

In solving optimal design problems, regularities are found which can be generalized to formulate axiomatical statements - postulates $[1,2]$. Using them in creating optimization algorithms allows clearer understanding of ways of achieving goals, i.e. simplifying problem solving.

1. Increase in the degree of equal strength generally reduces the objective function value. The lowest value of the objective function is reached in the system with fully equal strength.

2. Increase in the number of project variables with the unchanged system of stress-strain state restrictions either results in decreasing of the objective function of the optimal solution or leaves it unchanged.

3. With the permanent number of project variables, adding restrictions narrows the range of feasible solutions and cannot reduce the value of the objective function of the optimal solution - it either remains unchanged or increases.

\footnotetext{
* Corresponding author: sinchuk.sophia@gmail.com
} 


\subsection{Optimization technique}

On the basis of the above postulates, an optimization method for a truss beam is proposed, which is based on following aspects:

1. In combined beam structures, the material consumption is determined by elements that experience a stressed state in the form of bending compression.

2. In the elements exposed to bending compression, the reduction in the cross-section is determined rather by the reduction of the bending moment.

3. Bending moments increase from the pillar to the middle of the span.

4. Truss beams belong to spacer systems, which also include arches. Thus, both have some common properties, for example, in tree-hinged statically determinate arches, the cross-sections are affected by eccentric compression i.e. a bending moment and a longitudinal force appear in them. Naturally, the lower the values of bending moments are, the smaller the cross-sectional dimensions are, based on the strength condition, which means less material consumption for making the arch and less costs. Therefore, a rational or an optimal arch, affected, for example, only by constant load, it generally understood as an arch the axis of which is described as a funicular curve determined by the type of load. In all cross-sections of such an arch, bending moments are equal to zero and its manufacture requires less material then that of arches described by other curves.

It can be assumed that truss beams also have this property under certain conditions. Particularly, if the lower truss boom is determined along a curve corresponding to the acting constant load and the braces of the beam element form a continuum with the lower truss boom, then bending moments in the beam elements are equal to zero.

In fact, the truss beam design (Fig. 1) assumes that the braces of the beam element and lower truss boom are made in the form of a limited number of rods (pillars). As a result, bending moments still appear in the beam - negative ones over the pillars and mostly positive between them. Their values depend on the number of pillars and their location in the span. The values of some moments increase, while others decrease when the position of the pillars changes. Rational is such an arrangement in which the absolute values of the moments are equalized and are the lowest [3].

5. Bending moments do not depend on the truss boom if the truss rod is delineated by the funicular curve for the three-hinged arch [4-6]. This will be seen from formulas (1) and (2) below

$$
\begin{aligned}
M_{j}^{\text {sup }} & =\frac{q\left(\ell-x_{j}\right) x_{j}}{2}\left[1-\frac{\ell^{2}}{4\left(\ell-x_{n / 2}\right) x_{n / 2}}\right], j=1,2, \ldots, n / 2, \\
M_{j}^{\max } & =\frac{q \ell}{2} x_{j, \max }-\frac{q\left(x_{j, \max }\right)^{2}}{2}-\frac{q \ell^{2}}{8\left(\ell-x_{n / 2}\right) x_{n / 2}}\left[\left(\ell-x_{j-1}\right) x_{j-1}+\right. \\
& \left.+\frac{\left(\ell-x_{j}\right) x_{j}-\left(\ell-x_{j-1}\right) x_{j-1}}{z_{j}}\left(x_{j, \max }-x_{j-1}\right)\right], j=1,2, \ldots, n / 2,
\end{aligned}
$$

where $x_{j, \max }-$ distance from the beam beginning to the extreme in the $j$ th panel,

$$
x_{j, \max }=\frac{\ell}{2}\left\{1-\frac{\ell\left[\left(\ell-x_{j}\right) x_{j}-\left(\ell-x_{j-1}\right) x_{j-1}\right]}{4 z_{j}\left(\ell-x_{n / 2}\right) x_{n / 2}}\right\} .
$$


Based on the analysis of the above positions, the method for truss beam optimization is proposed, which is based on the minimization not of volume, but of the bending moments in the beam element of construction, i.e.

$$
M_{\text {culc }}=\max _{j=1,2, \ldots, n / 2}\left(\left|M_{j}^{\text {sup }}\right|,\left|M_{j}^{\max }\right|\right) \rightarrow \min ,
$$

where $M_{j}^{\text {sup }}$ - bending moment in the beam element cross-section above the $j$ th pillar; $M_{j}^{\max }$ - extreme bending moment in the cross-section between $(j-1)$ th and the $j$ th pillars (within the limits of the $j$ th panel).

Two optimality conditions must be satisfied herein. The first condition

$$
\left|M_{n / 2}^{\text {sup }}\right|=\left|M_{n / 2}^{\max }\right|
$$

must be satisfied every time.

The second condition will be different, it is chosen depending on the type of optimized beam element design:

- with constant cross-section of a beam element along the entire span length

$$
M_{j}^{\max }=M_{n / 2}^{\max }, \quad j=1,2, \ldots, n / 2-1 ;
$$

- with piecewise constant cross-section of a beam element (constant in the intervals between the pillars)

$$
M_{j}^{\max }=\left|M_{j}^{\text {sup }}\right|, \quad j=1,2, \ldots, n / 2-1 .
$$

\section{Calculation results}

\subsection{Calculation results for a truss beam under action of constant load}

Span beam is accepted $\ell=24 \mathrm{~m}$; boom $f=3.6 \mathrm{~m}$; distributed load intensity $q=60 \mathrm{kN} / \mathrm{m}$; number of pillars connecting the beam element with the lower truss boom $n=6$; beam material - steel (design resistance $m R_{y}=200 \mathrm{MPa}$ ). The beam element has a rectangular cross-section with the height to width ratio $h / b=5$; pillars and lower truss beam elements have annular cross-section with a diameter $D$ and wall thickness $0.025 D$ [7].

$q=60 \mathrm{kN} / \mathrm{m}$

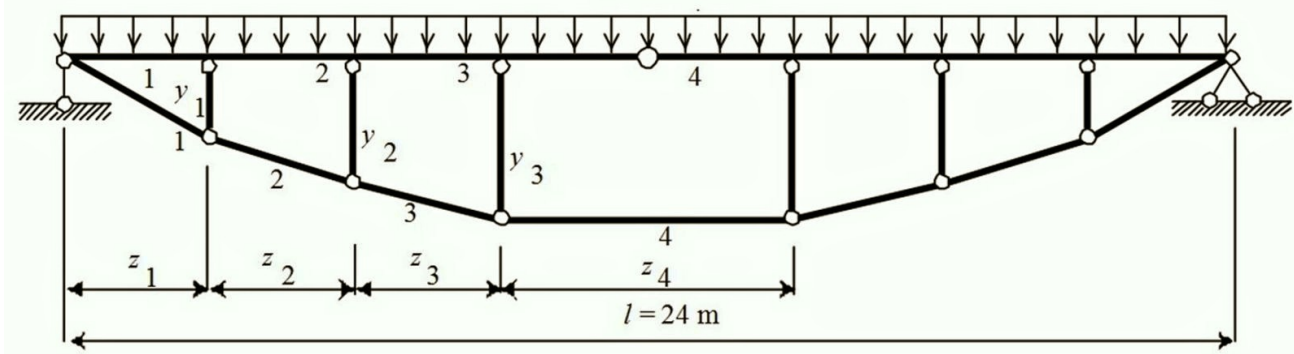

Fig. 1. Truss beam diagram and numbering of its elements.

Next, we will change each value $z_{j}, j=1, \ldots, n / 2$ with the earlier chosen increment, 
for example, $\Delta z=0.01 \mathrm{~m}$ until a condition specified below is achieved. The rules of change $z_{j}$ are given in the description of the optimization process [3].

Table 1. Calculation results.

\begin{tabular}{|c|c|c|c|c|c|c|c|c|c|}
\hline \multirow{2}{*}{ Approximation } & \multicolumn{3}{|c|}{ Value $z, \mathrm{~m}$} & \multicolumn{6}{c|}{ Moments value, $\mathrm{kNm}$} \\
\cline { 2 - 10 } & $z_{1}$ & $z_{2}$ & $z_{3}$ & $M_{1}^{\max }$ & $M_{1}^{\text {sup }}$ & $M_{2}^{\max }$ & $M_{2}^{\text {sup }}$ & $M_{3}^{\max }$ & $M_{3}^{\text {sup }}$ \\
\hline 0 & 3 & 3 & 3 & 19.2 & -126 & -96 & -216 & -172.8 & -270 \\
\hline Optimal & 3.11 & 3.60 & 3.88 & 59.5 & -27.3 & 59.5 & -48.7 & 58.8 & -59.6 \\
\hline
\end{tabular}

The construction is designed and calculated in LIRA software complex to verify the obtained data.

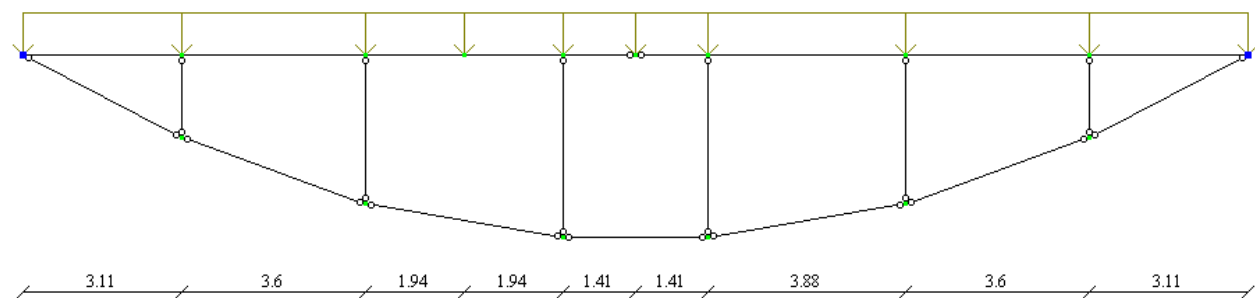

Fig. 2. The optimal truss beam design under action of constant load.

Values of forces, cross-sectional areas, and volumes of lower elements on all optimization approximations are given in Table 2.

Table 2. Results of the truss beam optimization.

\begin{tabular}{|c|c|c|c|c|c|c|c|c|c|c|}
\hline & \multicolumn{3}{|c|}{ Pillars } & \multicolumn{3}{|c|}{$\begin{array}{l}\text { Beam } \\
\text { element }\end{array}$} & \multicolumn{4}{|c|}{ Lower belt } \\
\hline $\begin{array}{c}0 \\
0 \\
\text { approximation }\end{array}$ & 1 & 2 & 3 & 1 & \begin{tabular}{|l|l|}
2 & 3
\end{tabular} & 4 & 1 & 2 & 3 & 4 \\
\hline$N, \mathrm{kN}$ & -192 & -192 & -288 & \multicolumn{3}{|c|}{1280} & 1446 & 1367 & 1312 & 1280 \\
\hline$M_{\max }, \mathrm{kNm}$ & & & & \multicolumn{3}{|c|}{270} & & & & \\
\hline$A, \mathrm{~cm}^{2}$ & 9.6 & 11.34 & 17.1 & \multicolumn{3}{|c|}{280.13} & 72.28 & 68.35 & 65.6 & 64 \\
\hline$V, \mathrm{~cm}^{3}$ & \multicolumn{3}{|c|}{20689.39} & \multicolumn{3}{|c|}{673014.50} & \multicolumn{4}{|c|}{171528.00} \\
\hline & \multicolumn{10}{|c|}{$V=865231.9 \mathrm{~cm}^{3}$} \\
\hline $\begin{array}{c}\text { Optimal } \\
\text { approximation }\end{array}$ & 1 & 2 & 3 & 1 & \begin{tabular}{l|l}
2 & 3 \\
\end{tabular} & 4 & 1 & 2 & 3 & 4 \\
\hline$N, \mathrm{kN}$ & -204. & -227.5 & -203.8 & \multirow{2}{*}{\multicolumn{3}{|c|}{1217}} & 1373 & 1291 & 1234 & 1217 \\
\hline$M_{\max }, \mathrm{kNm}$ & & & & \multirow{2}{*}{\multicolumn{3}{|c|}{$\frac{59.5}{130.68}$}} & & & & \\
\hline$A, \mathrm{~cm}^{2}$ & 10.21 & 13.40 & 13.18 & & & & 68.64 & 64.55 & 61.69 & 60.84 \\
\hline$V, \mathrm{~cm}^{3}$ & & 20444.0 & & \multicolumn{3}{|c|}{$\frac{130.68}{314014.4}$} & \multicolumn{4}{|c|}{163166.8} \\
\hline & \multicolumn{10}{|c|}{$V=497625.2 \mathrm{~cm}^{3}($ decreased by $45.6 \%)$} \\
\hline
\end{tabular}

As a result of calculation in LIRA software complex, a diagram of longitudinal forces (Fig. 3) and of bended moments (Fig. 4) were obtained. 


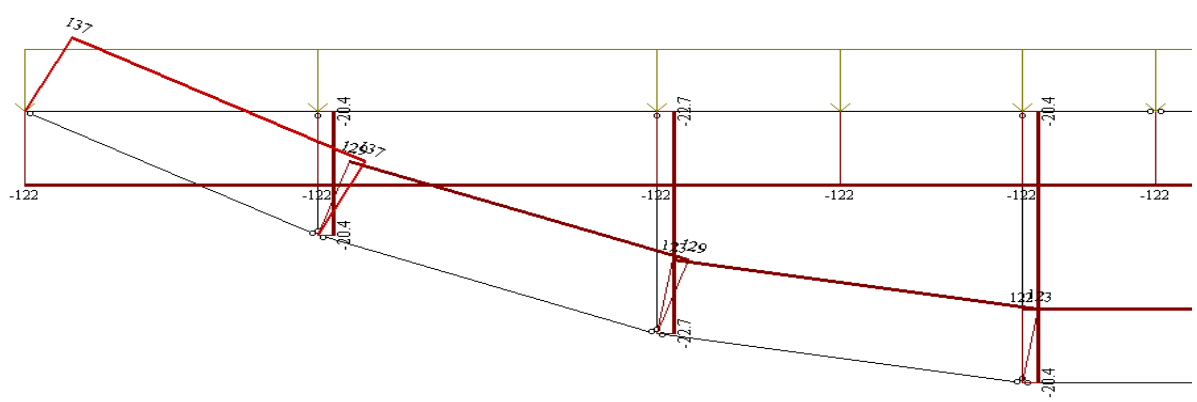

Fig. 3. The diagram of longitudinal forces arising in the truss beam under action of constant load, $t$.

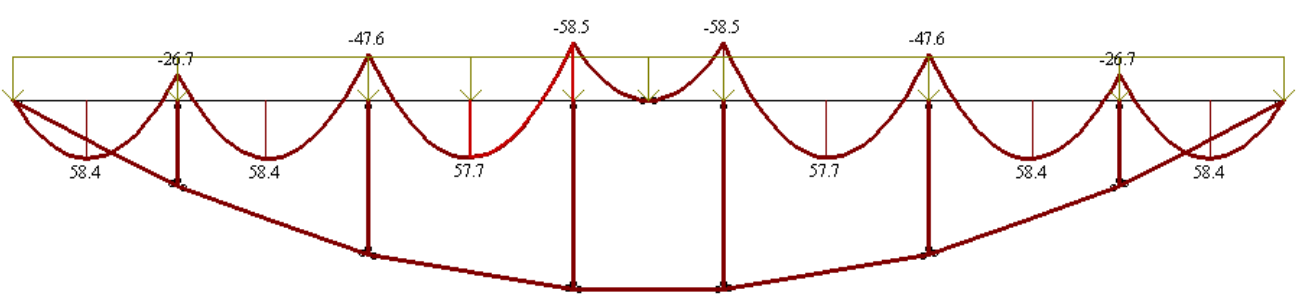

Fig. 4. The bending moments diagram arising in the truss beam under action of constant load, $\mathrm{kNm}$.

Comparing the results of the design calculation with the action of constant load with the calculated ones, obtained an infelicity of $0.06 \%$ and $0.05 \%$, respectively.

\subsection{Calculation results for a truss beam under action of constant and temporary load}

To obtain the optimal beam design, we will assume the precondition substantiated above [8]. In addition, we assume here that under the combined action of loads - uniform constant load $q=$ const and pedestrian load $p=$ const it would be rational to position the nodes of the lower boom on a square parabola, as under action of only constant load. The expression for determining the ordinates of such a curve is

$$
y=\frac{4 f x(\ell-x)}{\ell^{2}},
$$

where $f$-theoretical sagitta of parabola, on which the nodes of the lower boom are positioned.

Considering (8), influence line ordinates (9)-(13) are:

$$
\begin{gathered}
a_{j}=\frac{x_{j}\left(\ell-x_{j}\right)}{\ell}-\frac{x_{j}^{2}\left(\ell-x_{j}\right)}{2 x_{n / 2}\left(\ell-x_{n / 2}\right)}=\frac{x_{j}\left(\ell-x_{j}\right)}{\ell}\left[1-\frac{x_{j} \ell}{2 x_{n / 2}\left(\ell-x_{n / 2}\right)}\right], \\
b_{j}=\frac{x_{j}}{2}\left[1-\frac{\ell\left(\ell-x_{j}\right)}{2 x_{n / 2}\left(\ell-x_{n / 2}\right)}\right], \\
M_{j}^{q}=\frac{q}{2}\left[a_{j} u_{j}+b_{j}\left(\ell-u_{j}\right)\right],
\end{gathered}
$$




$$
\begin{gathered}
M_{j}^{-p}=\frac{p}{2} b_{j}\left(\ell-u_{j}\right), \\
M_{j}^{q-p}=\frac{q}{2} a_{j} u_{j}+\frac{q+p}{2} b_{j}\left(\ell-u_{j}\right) .
\end{gathered}
$$

On the basis of the properties of truss beams described above, we can formulate the following algorithm for choosing the optimal panel dimensions $z_{j}, j=1,2, \ldots, n / 2$.

The arrangement of nodes is optimal if all values of the maximum span moments $M_{j}^{\max }=M_{j}^{q+p}\left(x_{j, \max }\right)$ and all values of the moments at support $M_{j}^{\text {sup }}=M_{j}^{q-p}\left(x_{j}\right)$ have minimum values. The experience of optimizing the truss beam under action of constant load shows that in such case, these moments become approximately equal, which means equal strength of the system.

The following actions are performed to achieve these conditions.

The initial values are chosen $z_{j}$, for example,

$$
\begin{gathered}
z_{j}^{(0)}=\frac{\ell}{2(n / 2+1)}, j=1, \ldots, n / 2, \\
x_{j}^{(0)}=\sum_{k=1}^{j} z_{k}^{(0)}, j=1, \ldots, n / 2 .
\end{gathered}
$$

Values $M_{j}^{\text {sup }}=M_{j}^{q-p}\left(x_{j}^{(0)}\right)$ are calculated according to (14).

$$
M_{j}^{q-p}=\frac{q}{2} a_{j} u_{j}+\frac{q+p}{2} b_{j}\left(\ell-u_{j}\right)
$$

Values $M_{j}^{\max }=M_{j}^{q+p}\left(x_{j, \max }\right)$ are calculated, where the extremum point $x_{j, \max }$ is determined from equation

$$
\frac{q+p}{2}\left(\frac{\partial a_{j x}}{\partial x} u_{j x}+a_{j x} \frac{\partial u_{j x}}{\partial x}\right)+\frac{q}{2}\left[\frac{\partial b_{j x}}{\partial x}\left(\ell-u_{j x}\right)-b_{j x} \frac{\partial u_{j x}}{\partial x}\right]=0
$$

The increments are specified $z_{j}^{(1)}=z_{j}^{(0)}+\Delta z_{j}$.

If $\left.\max _{j=1, n / 2}\left(M_{j}^{q+p}\left(x_{j, \max }^{(1)}\right), \mid M_{j}^{q-p}\left(x_{j}^{(1)}\right)\right)<\max _{j=1, n / 2}\left(M_{j}^{q+p}\left(x_{j, \max }^{(0)}\right), \mid M_{j}^{q-p}\left(x_{j}^{(0)}\right)\right)\right), \quad$ then $\quad x_{j}^{(1)} \quad$ are accepted as new values $x_{j}$ (and respectively $z_{j}$ ).

Similarly, increments are specified in an arbitrary order $z_{j}^{(m)}=z_{j}^{(m-1)}+\Delta z_{j}, j=1, \ldots, n_{j}$. Values $M_{j}^{\text {sup }}=M_{j}^{q-p}\left(x_{j}^{(m)}\right)$ are calculating according to (14).

Values $M_{j}^{\max }=M_{j}^{q+p}\left(x_{j, \max }^{(m)}\right)$ are calculated, where the extremum point $x_{j, \max }^{(m)}$ is determined from equation (15).

If $\left.\max _{j=1, n / 2}\left(M_{j}^{q+p}\left(x_{j, \max }^{(m)}\right), \mid M_{j}^{q-p}\left(x_{j}^{(m)}\right)\right)<\max _{j=1, n / 2}\left(M_{j}^{q+p}\left(x_{j, \max }^{(m-1)}\right), \mid M_{j}^{q-p}\left(x_{j}^{(m-1)}\right)\right)\right)$, then $x_{j}^{(m)}$ are accepted as new values $x_{j}$ (and respectively $z_{j}$ ). 
The process continues until $x_{j}$ reaches some values limited by the design features of the system, for example, $x_{n / 2}<\ell / 2$. Values $z_{j}, j=1, \ldots, n / 2$ obtained at the last approximation are accepted as optimal $z_{j}^{\text {opt }}$.

The proposed algorithm is used to optimize the truss beam given above with the calculation of the structure under action of constant load (Fig. 1) with the same dimensions and initial data. Moving load is accepted $p_{1}=p_{2}=p=q=6 \mathrm{tf} / \mathrm{m}$. Initial values $z_{1}^{(0)}=z_{2}^{(0)}=z_{3}^{(0)}=3 m$. The obtained optimization results are given in Table 3 .

Table 3. Calculation results.

\begin{tabular}{|c|c|c|}
\hline$z=M$ & $M^{\max }, \mathrm{kNm}$ & $M^{\text {sup }}, \mathrm{kNm}$ \\
\hline$z_{1}=4.50 m$ & 671.4 & -673.8 \\
\hline$z_{2}=2.58 m$ & 673.7 & -673.6 \\
\hline$z_{3}=3.70 m$ & 600.1 & -276.0 \\
\hline
\end{tabular}

The construction is designed and calculated in LIRA software complex to verify the obtained data.

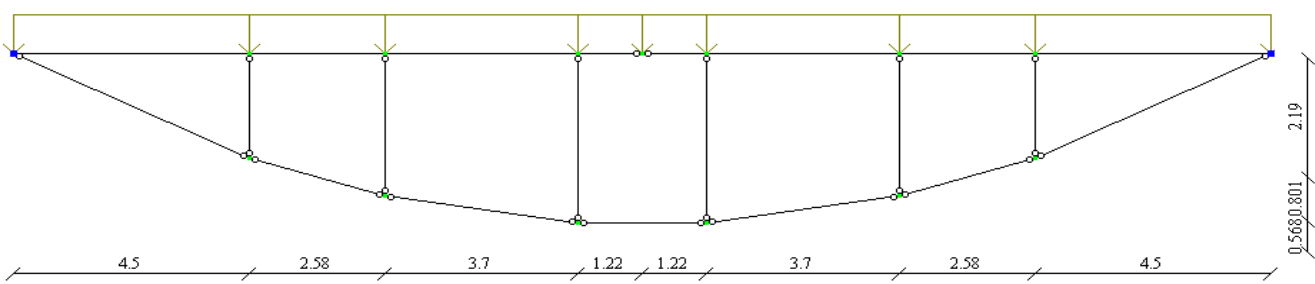

Fig. 5. The optimal truss beam design under action of constant and temporary load.

The calculation results on the initial (at $z_{j}^{(0)}$ ) and the final (at $z_{j}^{\text {opt }}$ ) optimization approximation are shown in Table 4.

Table 4. Results of optimization of the truss beam.

\begin{tabular}{|c|c|c|c|c|c|c|c|c|c|c|}
\hline & \multicolumn{3}{|c|}{ Pillars } & \multicolumn{3}{|c|}{$\begin{array}{l}\text { Beam } \\
\text { element }\end{array}$} & \multicolumn{4}{|c|}{ Lower belt } \\
\hline $\begin{array}{c}0 \\
\text { approximation }\end{array}$ & 1 & 2 & 3 & 1 & \begin{tabular}{l|l}
2 & 3
\end{tabular} & 4 & 1 & 2 & 3 & 4 \\
\hline$N, \mathrm{kN}$ & -384 & -384 & -576 & \multirow{2}{*}{\multicolumn{3}{|c|}{$\begin{array}{l}2560 \\
1014\end{array}$}} & 2891 & 2734 & 2324 & 2560 \\
\hline$M_{\max }, \mathrm{kNm}$ & & & & & & & & & & \\
\hline$A, \mathrm{~cm}^{2}$ & 19.2 & 19.2 & 28.8 & \multicolumn{3}{|c|}{657.8} & 144.6 & 136.7 & 131.2 & 128 \\
\hline$V, \mathrm{~cm}^{3}$ & \multicolumn{3}{|c|}{35856} & & 578656 & & \multicolumn{4}{|c|}{343056} \\
\hline & \multicolumn{10}{|c|}{$V=1957568 \mathrm{~cm}^{3}$} \\
\hline $\begin{array}{c}\text { Optimal } \\
\text { approximation }\end{array}$ & 1 & 2 & 3 & 1 & \begin{tabular}{l|l}
2 & 3
\end{tabular} & 4 & 1 & 2 & 3 & 4 \\
\hline$N, \mathrm{kN}$ & -429.2 & -380.7 & -372.2 & \multirow{2}{*}{\multicolumn{3}{|c|}{2425}} & 2698 & 2539 & 2453 & 2425 \\
\hline$M_{\max }, \mathrm{kNm}$ & & & & \multirow{2}{*}{\multicolumn{3}{|c|}{$\begin{array}{l}673.8 \\
518.23\end{array}$}} & & & & \\
\hline$A, \mathrm{~cm}^{2}$ & 21.46 & 19.04 & 21.73 & & & & 134.9 & 127.0 & 122.7 & 121.3 \\
\hline$V, \mathrm{~cm}^{3}$ & \multicolumn{3}{|c|}{36305.6} & \multicolumn{3}{|c|}{1243751.0} & \multicolumn{4}{|c|}{325089.1} \\
\hline & & & $V=1605$ & 46 & $\mathrm{~cm}^{3}(\mathrm{de}$ & & 1 & $\%)$ & & \\
\hline
\end{tabular}




\section{Conclusion}

Analysis of the possibilities of structure designing in LIRA software complex suggested that in this software complex, only the pedestrian load cannot be applied during calculating the mobile load. The calculation will be carried out only when the structure is loaded with vehicle or rolling stock mobile load, and the pedestrian load will be considered as an additional one within the sidewalks $[9,10]$.

The proposed optimization algorithm for combined structures allows calculating the design when any kinds of loads and their combinations are applied. The results are verified for compliance with the conditions of strength limitations, stability and structural flexibility limitations of the rods.

\section{References}

1. A.I. Vinogradov, Problema optimalnogo proektirovaniia v stroitelnoi mekhanike (Vyscha shkola, Kharkiv, 1973).

2. E.D. Chikhladze, G.L. Vatulia, Yu.P. Kitov, Osnovy rascheta $i$ proektirovaniia kombinirovannykh i stalebetonnykh konstruktsii (Transport, Kiev, 2006).

3. Yu.P. Kitov, G.L. Vatulia, M.A. Verevicheva, Zb. nauk. prats / CSP, UkrDAZT 143, $124-131$ (2014).

4. S.P. Fesyk, Spravochnik po soprotivleniyu materialov (Budivelnyk, Kyiv, 1982).

5. E. Hog, Prikladnoe optimalnoe proektirovanie (Mir, Moskva, 1983).

6. P.M. Salamakhin, Tr. Izd. 4, 20-23 (2005).

7. SSN V.2. 3-14:2006. Mosty ta truby. Pravyla proektuvannia. (MBAZKH, Kyiv, 2006).

8. Yu. Kitov, M. Verevicheva, G. Vatulia, Ye. Orel, S. Deryzemlia Matec Web of Conferences, 133, 03001 (2017).

9. A.S. Gorodetsky, Yu. D. Geraimovych, D.V. Marchenko, SADC and G. 1, 70-74, (2010).

10. D.A. Gorodetsky, M.S. Barabash, R.Yu. Vodopyanov, V.P. Titok, A.E. Artamanova, Programmnyi kompleks LIRA-SAPR (Kyiv-Moscow, 2013). 